\title{
Digital Disruption: A Conceptual Clarification
}

\author{
Abayomi Baiyere \\ Copenhagen Business School \\ aba.digi@cbs.dk
}

\author{
Philipp Hukal \\ Copenhagen Business School \\ ph.digi@cbs.dk
}

\begin{abstract}
Digital disruption is widely used as a shorthand label to describe digital innovation phenomena -- often without paying enough attention to the properties of digital, disruptive, and innovative. As a result, the term lacks precision and confounds phenomena that are neither digital nor disruptive innovations. Yet without these theoretical foundation the concept is rendered meaningless. In this paper, we conceptualize digital disruption by attending to its properties stemming from its roots in digital innovation and disruptive innovation. In doing so, we add to past work by attending to the idea of digital disruption beyond the fad.
\end{abstract}

\section{Introduction}

It is undisputed that digitally-enabled innovation helps organizations create novel offerings at unprecedented speed, scale, and scope [5, 33, 40]. Such digital innovations are often seen as radical due to the fundamental reconfiguration of markets and industries they help create. Indeed, because of the extent of their alterations of the status quo, many digital innovations have been labelled 'digital disruptions' [21]. This term has been used so widely and with so little regard to its conceptual underpinning that it risks confounding what makes something an innovation, digital, or disruptive. In this paper, we seek to clarify the concept of digital disruption [7, 21, 38]. We build on prior work [34, 36] to define Digital Disruption as: the alteration of $a$ domain-specific paradigm due to the digital attributes of an innovation. Riemer and Johnston (2019) capture the notion of disruption as a change so fundamental and seemingly radical that is often beyond recognition by actors that are incumbent to a domain such as an organization, market, or industry. The term 'Digital Disruption' however, lacks theoretical underpinnings in the literature. Through this work, we propose a view that aims at conceptual clarity in order to allow for a consistent understanding and usage of the term.
Digital Disruption is rooted in two separate theoretical foundations: Disruptive Innovation [9, 11], and Digital Innovation [40]. Yet, not much can be said about the theoretical glue that holds them together as foundational pillars of digital disruption. The term digital disruption has been introduced from the nonacademic domain, but due to its potential importance and theoretical relevance, it is increasingly being used in academic circles [21, 38]. Yet, the loose usage if not addressed, can hamper utility of the concept for future scholarship [34]. For example, in many of the prior studies invoking the concept, it is taken as a given and rarely defined [7, 14, 21, 35]. This conceptual laxity may be understandable. It is hard to argue against the transformative potential of digitalization. However, there is surprisingly little effort at theorizing what makes Digital Disruption either digital or disruptive. Hence, some of the open questions worth exploring include - what constitutes a digital disruption? What are the unique properties of digital disruption that separates it from other types of innovations and disruptions? This paper addresses these questions in order to extend our understanding of digital disruption and derive theoretical propositions that may guide future theorizing.

We argue that this is particularly pertinent since one of the key concepts on which digital disruption is based is disruptive innovation, which has been largely misconstrued and misrepresented both in scholarly and practitioner literature $[8,23]$. This is particularly evident in unresolved debates such as - a) disruptive innovation as low end versus high end disruption, b) ex ante versus ex post theory, c) radical versus disruptive versus discontinuous innovation, d) disruptive innovation versus disruptive technology terminology, e) disruptive by design versus disruptive by time, too mention only a few $[3,9,11,12,16,30]$. Creating consensus about digital disruption is thus crucial in order to advance future research. To that end, conceptual clarification of what characterizes a digital disruption that draws on its properties of digital, disruptive, and innovation is necessary and valuable. 


\section{Digital Disruption: Theoretical Foundations}

Digital disruption as a theoretical term has been used to describe changes to the established modalities of operation or functioning in a given context due to the influence of digitalization [21, 35, 38]. Such changes are typically trajectory-shifting in the way they force a reorientation of how things are done or perceived in that context [5]. Another way to conceive of digital disruption is to see it as inertia-breaking. This draws from the formulation of inertia in physics where inertia describes the tendency of a body to remain at rest or to continue in a state of constant motion, except compelled to change its state by a force. Thus, inertiabreaking as a description of digital disruption, implies that digitalization changes the status quo or paradigm (pattern, routine, practice e.t.c) that characterizes a given domain [34] Furthermore, digital disruption takes a purview that expands beyond the market focus. As shown by prior studies, the domain of digital disruption maybe at the industrial level [14, 21]; organizational level [7, 38]; or societal level [35].

For our theoretical background, we draw largely on prior literature and reflective examples to highlight the attributes and defining characteristics of digital disruption. As is typical of a conceptual study, this paper is grounded in a synthesis of current usage of prior research and existing theoretical base. As such we review studies from both innovation management and information systems to highlight the origin of digital disruption from its two distinct theoretical foundations $[21,34,36]$. We also draw on past studies that have evoked the concept of digital disruption to enhance our theoretical positioning, and to include illustrative examples for our proposed conceptualization.

\subsection{Disruptive Innovation}

The first theoretical concept related to digital disruption is disruptive innovation. The conceptualization of disruptive innovation has been around for over two decades [9]. A copious amount of studies has been carried out to better understand and extend the theory since then. Despite several attempts for clarification and extension [3, 41], disruptive innovation has long faced critique due to various misconception and misuse of the term. In its primary form, disruptive innovations can be described as innovations that lead to the decimation of another entity (such as a product, a company or even an industry). It typical sets out to attack the fringes of a market but grows gradually to a point that it unseats an incumbent from its position in the market [16].
Drawing from the received knowledge about disruptive innovation studies, we outline three defining characteristics of disruptive innovation that hold relevance for theorizing about digital disruption [11, $16,30]$. These are impact, relativity and temporality.

2.1.1. Impact: This is a characteristic of a disruptive innovation that shifts the attention of the disruption from the novelty of the innovation itself to the impact that the innovation creates. In other words, the disruptiveness of an innovation is not necessarily because of the superiority of the innovation, rather its disruptiveness is a measure of the effect of the innovation on an incumbent $[11,16]$. For example, the disruption of the mainframe computers by minicomputers and the subsequent disruption of the minicomputer market by PC (personal computers) is a story of David beating Goliath $[9,15]$. In this example, a more inferior innovation in terms of processing power, storage capacity, among many other metrics valued by the mainstream customers, disrupted a more powerful and advanced technology. A similar case can be made for the disruption of the integrated mills of the steel industry by the mini mills or the disruption of Xerox copiers by the inferior Canon photocopiers, among several other examples $[9,11]$.

2.1.2. Relativity: A typical misconception of disruptive innovations is that innovations can be considered a disruptive innovation in and of themselves alone. The relativity attribute of disruptive innovation emphasizes that disruption is a relative concept, which implies that in order for an innovation to qualify as a disruptive innovation, there should be an identifiable entity that it has disrupted $[1,2,9]$. The implication of this attribute is that some innovation that are on a trajectory to be disruptive or innovations with the tendencies of becoming disruptive, would at best qualify as potential disruptive innovation. For example, it is not uncommon for entrepreneurs to describe their early stage innovations as disruptive. This logic also characterizes the classification of budding innovations such as bitcoin, 3D printing or Tesla as disruptive innovations - rather than potential disruptive innovations $[2,10,31]$.

2.1.3. Temporality: Disruption as captured by the concept of disruptive innovation is inherently temporal. This is because disruption can be conceived as a process that unfolds over time. This is particularly the case when the incumbent would have the opportunity to respond and deflect the disruption. In some cases, they fail to do so [34] and in some cases they are able to respond to a potential disruption [22]. Temporality of disruptive innovations also captures the lifecycle of 
innovations. The status of being disruptive can dissolve over time as the disruptor gradually grows and matures until it becomes an incumbent and a ripe candidate to be also disrupted $[16,30]$. An example can be seen in the rise of Toyota as a disrupter to the automotive industry with its cheaper cars [11]. With time, however, Toyota grew to become an incumbent itself and currently finds itself having to respond to the disruptive threat of the emergence of the sharing economy and autonomous cars that are besetting the automotive industry. Hence, the disruptive status of an innovation is a function of time and the time horizon under consideration in its lifetime.

\subsection{Digital Innovation}

The second theoretical concept related to digital disruption is digital innovation. Digital innovation is rooted in literature on information systems, computer science as well as innovation management $[13,26,33$, 40]. We define digital innovation as the "(re)combining digital technology to create of novel outputs" [19]. Three aspects characterize this understanding of digital innovation: digital technology, recombination and generativity.

2.2.1. Digital Technology: The first defining characteristic of these innovations stems from the unique properties of digital technology used to innovate [19, 39]. In contrast to physical material, digital technology artifacts interoperate on the basis of accessing and manipulating a common resource; digitally stored information. The ability to handle digital information characterizes the unique attributes of digital technology [20,40]. Three such attributes are of particular relevance for innovating with digital technology: First, its homogeneity: once digitized, information in digital form can be stored, transformed, and transmitted by any digital technology with computing capabilities -- irrespective of the content of digital information [40]. Second, digital technology is editable through means of re-programming, making digital technology malleable to changes after the fact by interaction with actors and technologies distributed in time and space [20]. And third, digital technology is self-referential as digital information is needed to create digital technology $[18,39]$. Digital technology is hence both the result of and the basis for developing digital innovations.

2.2.2. Recombination: The unique attributes of digital technology fuel two interrelated processes; digitization and digitalization [37]. Driven by rapid advances in developments of computing technology, the availability and affordability of performant and connective devices contribute to the ubiquity of digitally stored information. Digitization describes the process of representing information in digital form - be that information stored in existing repositories or generating new information. This is mirrored by the process of digitalization, i.e. the widespread use and application of digital technology. In combination, the dynamics of digitization and digitalization [37] jointly enable diverse interaction and allow innovative inputs from sources and directions on innovation [40]. By exchanging and integrating resources through reciprocal connections, inputs for novel combinations are introduced from diverse origins across a network of participants $[4,28]$. Digital innovation is thus not the result of isolated activities by one focal organization. Instead, novel output is generated through dynamic cocreation processes of using technology components to interact with diverse repositories of digitally stored information.

2.2.3. Generativity: This relates to the capacity for expanding possibilities beyond the initial conception of a digital innovation that draws on leveraging the digital attributes of an innovation [17, 37]. Generativity captures the ability of a digital innovation to create, generate, or produce new content, structure or behavior and to be repurposed to meet emerging opportunities or constraints [37]. By its nature, digital innovations presents the potential to unlock affordances that may not have been previously conceived, which requires a degree of flexibility to accommodate and appropriately contextualize [40,42]. As an analogy, digital can be conceived of as clay in the hands of a potter, where the clay can be reshaped and can evolve into different forms beyond the wielders initial conceptions. In essence, generativity as a characteristics of digital innovation highlights the boundless possibilities to reconceptualize a current state in tandem with the everevolving potentials of digital technologies. It characterizes the emergent properties of digital that is due to the scale, diversity and dynamics of the digital technologies and the human agency to leverage these [27]. In general, the level of generativity can be said to differentiate digital innovations from other types of innovation [40]

\section{The Properties of Digital Disruption}

Building on the theoretical foundations of the digital disruption concept, we outline the digital and disruptive properties of the term to provide a footing for conceptual clarification. Our thesis is that these properties are essential considerations for delineating between what is a digital disruption, a digital 
innovation or a disruptive innovation. We elaborate on each and relate them to our proposed definition of digital disruption.

\subsection{Disruptive Property}

This property of digital disruption emphasizes the part of our definition that refers to "profound alteration in a prior paradigm". Essentially, the disruptive property stipulates that a digital disruption should have clearly identifiable change in the paradigm or status quo that has hitherto characterized a domain [34]. This builds on the impact, relativity and temporal characteristics inherited from the disruptive innovation roots of the concept. This altered change could take various forms depending on the domain or entity being disrupted [38]. This is in contrast with the dominant business domain (and organizational level) view with which the theory of disruptive innovation is premised. For example, it could unfold as changes to an economic configuration: alterations in the creation or capture of value that are paradigmatic to an industry, market, or network. Or it could unfold in a social domain, in which digital disruption may manifest itself in the manner through which it draws on its digital nature to alter existing social order that have hitherto justified current patterns of functioning or behavior [35].

Consider for instance how ride sharing apps are altering the value structure of the taxi industry. The disruptive property might also find expression in changes to technical trajectories via the displacement of prior technologies. For instance, the displacement of film photography by digital photography or the potential upending of subtractive manufacturing technologies with additive technologies like 3D printing. Third, disruptive properties might show in organizational reconfigurations in the form of competence destruction and competence creation, e.g., the shift from the creation of media content by expert journalists to the crowd-generated media content). Lastly, it can also involve, radical change in social structures (e.g. citizens micro-organizing on social media to have a voice towards government. Other examples abound [9, 21, 35, 38]. In summary, in order to fulfil the disruptive property, a digital disruption should, by definition, demonstrate the presence of an alteration in an existing logic that is paradigmatic to the domain in which the disruption occurs.

\subsection{Digital Property}

The digital property of digital disruption suggests that the disruption is induced, enabled or triggered by drawing on the unique attributes of digital technology in the process of creating the innovation in a domain. This relates to the "...due to the digital attributes of an innovation" part of our definition. It is identifiable by the use of recombining digital technology components in creating innovations [40]. The driving force behind such innovations are connected digital technology artifacts and the activity they afford [24, 27]. Digitality is characterized by the dynamics that foremost stem from the attributes of the underlying digital technology. In line with this, we argue that understanding Digital Disruption requires attention to the aspects of digital innovation as both are characterized by the dynamics induced when drawing from digital technology. Digital innovation as characterized in the section above is particularly relevant for the understanding of digital disruption. As the digitalization of innovation progresses, agency shifts from a pre-defined, centralized set of focal innovation agents, who steer and organize innovation processes, to decentralized innovation collectives with diverse goals, motives and capabilities [40]. Driven by the unique attributes of digital technology, digital disruption can be created through network of actors engaging with each other on the basis of digital innovation [28]

Digital Disruption requires a digital property. We would thus expect that the innovation in question is created using digital technology and its unique attributes. As such, the innovation is likely a recombination of digital technology components and involves inputs from a variety of sources. This can create unanticipated outcomes in line with the generative tendency of digital technology use. Innovating with digital technology can draw from an abundance of digital information due to the interoperability and connectivity of digital technology artifacts. The propensity of these characteristics of digital innovations to reshuffle value, reconfigure existing structures, blur boundaries, morph to accommodate emergent situations and unfold across different scope and scale with speed, makes it a potent constituent of digital disruption and hence, underlines the necessity to recognize the role of digital innovations in theorizing about Digital Disruption.

\subsection{Innovative Property}

By virtue of the two theoretical building blocks of digital disruption - digital innovation and disruptive innovations, an innovative property is an intrinsic property of digital disruption. Innovative in this sense is a property that captures the introduction of something new into the domain in which the digital disruption acts. This suggests that the change of the status quo in a given domain is induced by the 
introduction of novelty $[34,35,38]$. This draws from the basic formulation of innovation as the creation of something new or the enhancement of an existing element [29]. The novelty of any innovation is a function of the perspective of an observer. What is an innovation therefore requires an answer to the question of what is new to whom? Answering this question is a step towards identifying the domain in which a digital disruption is occurring. The question also echoes the distinction between process and product innovation. Actualizing innovation entails changes to the way outcomes are achieved or altering the outcome itself. In the context of digital disruption, the exchange of digital information on the basis of digital technology use can refer to both, processes and products $[28,33]$.

A useful way to think about the role of digital technology in such innovation activities is to distinguish between operant and operand resources [25, 28, 32]. As an operand resource, digital technology acts as means to an end and facilitates purposeful activity. In contrast, as an operant resource, digital technology is deployed as a purpose in and on itself. Lusch and Nambisan [25] use the example of the creation of a computer network: on the one hand, digital technology serves as facilitator as it enables the connection of digital technology components, thus contributing to form a network in the first place. On the other hand, the amalgam of the connected technology components forms an artefact itself. Hence the resulting network serves a purpose on its own. In digital disruption, innovations are created by leveraging the digital components in a given domain [6]. The role of digital technology in digital disruption thus varies depending on whether components enable an innovation, or are themselves forming the innovative composition. This distinction helps qualify digital disruption as it qualifies to whom the innovative property applies.

Table 1 provides an illustrative exposition of different examples of innovation as a function of varying configurations of disruptive, digital, and innovative properties. Consistent with our conceptualization we regard an innovation as a disruptive innovation if and only if all three properties are evident.

\begin{tabular}{|c|c|c|c|}
\hline Illustrative Example & Disruptive & Digital & Innovative \\
\hline $\begin{array}{l}\text { Netflix Streaming Video on } \\
\text { Demand: } \\
\text { Novel combination of digital } \\
\text { technology components to } \\
\text { create and capture value by } \\
\text { delivering, analyzing, and } \\
\text { producing digital video } \\
\text { content on demand. } \\
\text { Example extends to most } \\
\text { kinds of digital media content } \\
\text { e.g., music streaming (Riemer } \\
\text { and Johnston 2019) or e- } \\
\text { books (Utesheva et al. (2016) }\end{array}$ & $\begin{array}{l}\frac{\text { Yes: }}{\text { The economic }} \\
\text { paradigm of video on } \\
\text { demand was bound to } \\
\text { mediums requiring } \\
\text { branch networks to } \\
\text { obtain physical copies } \\
\text { of mediums holding } \\
\text { content (e.g., video, } \\
\text { DVD's). Content } \\
\text { production was the } \\
\text { result of major film } \\
\text { studios. Netflix } \\
\text { profoundly altered this } \\
\text { prior logic of film } \\
\text { production, delivery } \\
\text { and consumption }\end{array}$ & $\begin{array}{l}\text { Yes: } \\
\text { Digitized media content } \\
\text { is transmitted using } \\
\text { digital infrastructure } \\
\text { (network) and } \\
\text { components (apps, } \\
\text { service, devices); Content } \\
\text { can be consumed on a } \\
\text { variety end-user devices. } \\
\text { Trace data is collected to } \\
\text { analyze preferences } \\
\text { which in turn fuels } \\
\text { decisions on content } \\
\text { discovery and } \\
\text { production. }\end{array}$ & $\begin{array}{l}\frac{\text { Yes: }}{\text { New to customers: }} \\
\text { Video Streaming on } \\
\text { Demand offered a new to } \\
\text { consume video content } \\
\text { New to incumbents: } \\
\text { Incumbents (e.g., } \\
\text { Blockbuster) faced with } \\
\text { similar pressure to react } \\
\text { to technological } \\
\text { development }\end{array}$ \\
\hline
\end{tabular}




\begin{tabular}{|c|c|c|c|}
\hline $\begin{array}{l}\text { Fitness Tracking } \\
\text { Applications: } \\
\text { Novel configuration of } \\
\text { existing digital technology } \\
\text { components such as } \\
\text { smartphone GPS modules, } \\
\text { gyroscope, accelerometer, etc. } \\
\text { to collect data on the activity } \\
\text { of a device end-user }\end{array}$ & $\begin{array}{l}\text { No: } \\
\text { Does not } \\
\text { fundamentally } \\
\text { reconfigure industry } \\
\text { structures for most } \\
\text { incumbents: sports- } \\
\text { physicians, and } \\
\text { specialized equipment } \\
\text { manufacturers had } \\
\text { long standing } \\
\text { experience with } \\
\text { tracking athlete data. }\end{array}$ & $\begin{array}{l}\text { Yes: } \\
\text { Digital technology (e.g., } \\
\text { smartphone/watch) and } \\
\text { components (sensors } \\
\text { such as pedometer, } \\
\text { accelerometer, GPS) are } \\
\text { used to quantify physical } \\
\text { activity of the user. Add- } \\
\text { on functionality such as } \\
\text { data visualization, } \\
\text { analysis, and predictions } \\
\text { are used in software } \\
\text { applications to plan, } \\
\text { compare, and analyze } \\
\text { user fitness. }\end{array}$ & $\begin{array}{l}\text { Yes: } \\
\text { New to end-users: } \\
\text { Information on fitness } \\
\text { accessible to end-users } \\
\text { and on their mobile } \\
\text { devices. Use of specialist } \\
\text { physicians, special } \\
\text { stationary equipment not } \\
\text { required. }\end{array}$ \\
\hline Steam Engine & Yes: & No: & Yes: \\
\hline $\begin{array}{l}\text { Provided a means to use steam } \\
\text { as its working fluid in order to } \\
\text { carry out mechanical work } \\
\text { through the agency of heat. It } \\
\text { grew to replace sails on ships } \\
\text { just as steam locomotives } \\
\text { operated on the railway }\end{array}$ & $\begin{array}{l}\text { Disruptive in the } \\
\text { classical sense; } \\
\text { alternative product } \\
\text { were initially ignored } \\
\text { by incumbents. } \\
\text { Developments in lower } \\
\text { end market segments } \\
\text { fueled growth of new } \\
\text { product category, } \\
\text { usurping established } \\
\text { products }\end{array}$ & Not a digital innovation. & $\begin{array}{l}\text { Considered a } \\
\text { technological innovation } \\
\text { that led to major changes } \\
\text { in modern society } \\
\text { (Carlsen et al. 2010) }\end{array}$ \\
\hline
\end{tabular}

Table 1: Examples of digital disruption in relation to its properties and conceptual foundation.

\section{Conceptualizing Digital Disruption}

A search for explicit definitions of digital disruption within academic publications returns few results. Yet, the number of studies evoking the term seem to be on the rise. The term, however, receives

\begin{tabular}{|l|l|l|}
\hline Definition & Issues & Reference \\
\hline $\begin{array}{l}\text {. rapidly unfolding processes through which } \\
\text { digital innovation comes to fundamentally alter } \\
\text { historically sustainable logics for value creation } \\
\begin{array}{l}\text { and capture by unbundling and recombining } \\
\text { linkages among resources or generating new } \\
\text { ones. }\end{array}\end{array}$ & $\begin{array}{l}\text { - Focus on value creation and } \\
\text { capture limits other forms of } \\
\text { paradigmatic changes } \\
\text { - Formulated with a narrow focus on } \\
\text { business domains excludes other } \\
\text { domains }\end{array}$ & Skog et al. (2018) \\
$\begin{array}{l}\text {..change that occurs when new digital } \\
\text { technologies change customer experiences, } \\
\text { business processes, and business models, } \\
\text { thereby changing how value is cocreated. }\end{array}$ & $\begin{array}{l}\text { - Focus is solely on digital } \\
\text { technologies } \\
\text { - Focus on value limits other forms } \\
\text { of paradigmatic changes }\end{array}$ & $\begin{array}{l}\text { Bolton et al. } \\
(2019)\end{array}$ \\
\hline
\end{tabular}




\begin{tabular}{|c|c|c|}
\hline & $\begin{array}{l}\text { - Formulated with a narrow focus on } \\
\text { business domains }\end{array}$ & \\
\hline $\begin{array}{l}\text {...changes facilitated by digital technologies } \\
\text { that occur at a pace and magnitude that disrupt } \\
\text { established ways of value creation, social } \\
\text { interactions, doing business and more generally } \\
\text { our thinking. }\end{array}$ & $\begin{array}{l}\text { - Focus is solely on digital } \\
\text { technologies } \\
\text { - Focus on listed change options } \\
\text { limits other forms of paradigmatic } \\
\text { changes }\end{array}$ & $\begin{array}{l}\text { Sullivan and } \\
\text { Staib (2018) }\end{array}$ \\
\hline $\begin{array}{l}\text {... describes the effects that discontinuities have } \\
\text { for industry actors, most notably the threat that } \\
\text { new market entrants bring to the viability of } \\
\text { incumbent businesses. }\end{array}$ & $\begin{array}{l}\text { - Not exclusively focused on digital } \\
\text { technology }\end{array}$ & $\begin{array}{l}\text { Riemer and } \\
\text { Johnston (2019) }\end{array}$ \\
\hline \multicolumn{3}{|l|}{ Commonalities } \\
\hline $\begin{array}{l}\text { 1. Digital disruption involves an alteration } \\
\text { 2. Digital disruption results from the digita } \\
\text { 3. Digital disruption affects incumbents of }\end{array}$ & $\begin{array}{l}\text { f established paradigms } \\
\text { attributes of an innovation/technology } \\
\text { specific domain (social, economic, pol }\end{array}$ & ical, etc.) \\
\hline
\end{tabular}

Table 2: Prior definitions of Digital Disruption.

A comparison of existing definitions indicates some commonalities as well as differences in their formulation. Therefore, collectively, prior work provides a useful foundation for articulating an understanding of digital disruption. We abstract three key points that resonate across the usage of the term in academic discourse (See Table 1). Our articulation of the conceptual roots of digital disruption together with this prior work, paves the way for a clarification of the concept. We define digital disruption as:

the alteration of a domain-specific paradigm due to the digital attributes of an innovation.

With the notion of alteration we refer to the disruptive property which describes a fundamental reconfiguration of a status quo within a domain. By domain-specific paradigm we refer to the dominant established logic, norm, or routine, that has characterized a specific context. We use the term paradigm in line with [34] who draw in the Kuhnian view of paradigm shifts. A domain lends scope to delimit the context of a digital disruption. This could be for example, a purview on economic, social, organizational, individual, political, or technological aspects of a respective inquiry. By innovation, we allude to the inherent novelty that digital disruption presents in the context to which is applies. Lastly, digital attributes captures the digital property of a digital disruption and refers to the unique attributes of digital technology that can give rise to innovations.
Understanding a specific digital disruption requires attention to its domain specific characteristics. Hence, the idea of one universal logic of thinking that fits all digital disruption may not be useful for analytical purposes. Based on the plethora of cases in which digital disruption has been invoked, we posit that there is a need to identity the type of digital disruption in focus in other to be able to study it appropriately. After all, one can conceive of digital disruptions across a variety of contexts such as social, economic, or political domains. While the general idea of a profound alteration of an established paradigm (i.e. disruptive property) due to the digital attributes (i.e. digital property) remain important in establishing a digital disruption, the domain in question introduces nuances that require a different theoretical and analytical lens in unpacking what is novel about them (i.e. innovative property).

In our proposed definition, we have grounded our theorizing on the properties of digital disruption abstracted from prior knowledge on disruptive innovations and digital innovations. For effective utility of the concept, our clarification rests on the articulation of how digital disruption is related to these foundational roots. To that end, we illustrate the relationship between digital disruption, digital innovations and disruptive innovations in Figure 1 and present three corollaries to discuss the relationships. We present these corollaries as additions to our theoretical lexicon on digital disruption. We believe they hold analytical and practical utility. In combination, the corollaries provide a representation of 
the relationship between these two prior concepts and provides a useful apparatus for delineating them from digital disruption.

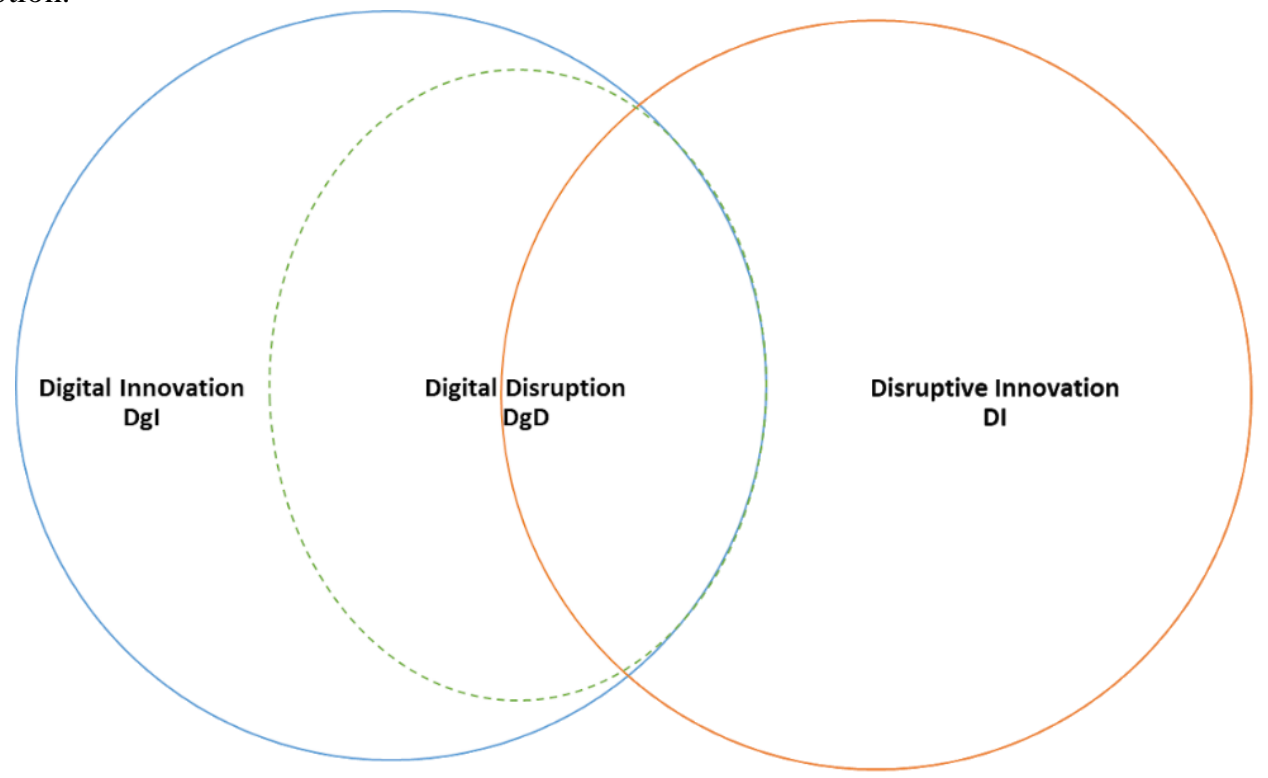

Figure 1: Relationship between Digital Disruption, Digital Innovations and Disruptive Innovations.

Corollary 1: Digital innovations are a necessary condition for Digital Disruption.

Digital innovations do not equate to digital disruption but a digital disruption is a digital

innovation $(\mathrm{DgI} \neq \mathrm{DgD}$ but $\mathrm{DgD}=\mathrm{DgI})$. Drawing from the properties of 'digitality', a digital disruption is by definition a digital innovation. However, the converse is not true as not all digital innovations are necessarily 'disruptive'. For example, the introduction of fitness tracking applications for smartphones were surely innovative. Yet, this digital innovation might not have been disruptive. Most suppliers of sports tracking equipment do still exist (e.g., Garmin) and have adjusted to the opportunity of providing dedicated applications in addition to OEM devices.

Corollary 2: Disruptive innovations are a necessary condition for Digital Disruption.

Although an innovation may be disruptive, that in itself does not qualify it to be a digital disruption (DI $\neq \mathrm{DgD}$ ). Such an innovation misses the 'digital' property that is necessary to qualify as a digital disruption. For example, the steam engine can be considered a disruptive innovation to sailing just as steel mini-mills were disruptive to integrated mills.
Yet none of these two examples was a digital disruption as they lack the digitality property.

Corollary 3: Digital Disruption is a sufficient condition for digital innovation and disruptive innovation.

If a digital innovation is a disruptive innovation, then it is also a digital disruption (If $\mathrm{DgI}=\mathrm{DI}$, then the $\mathrm{DgI}=\mathrm{DgD}$ ). An extension to the first two corollaries is that an innovation that is both digital and disruptive inherently falls under a digital disruption category. In other words, any claim to being a digital disruption would need to satisfy the requirements of its two conceptual roots, that is, exhibit both the 'digital' and 'disruptive' properties. For example, Netflix leverages digital technologies in a way that presents a fundamental shift to incumbents in industries such as content production, distribution, and consumption.

\section{Implications}

Drawing on this established premise of digital disruption, the implication of our conceptual development can be expressed via the call to attention on the defining properties of digital disruption as well as its linkage and delimitation from its conceptual roots. Consequently, we present two 
implications for future theorizing in practice and academe.

1. The disruptive property and digital property of digital disruption are necessary conditions for a digital disruption and both properties draw from its conceptual roots in digital innovations and disruptive innovations.

2. Although digital disruption draws from disruptive innovation and digital innovation in its conceptualization, it does not equate to either of them.

In conclusion, while digital disruption draws from digital innovations and disruptive innovations, it is important to realize the core aspects of these foundational theories that is relevant in studying digital disruption and the aspects that are not necessarily relevant. For example, disruptive innovations has been formulated to involve the encroachment of a market from the low-end or highend or even via a new market disruption $[9,11,16]$. This low-end, high-end or new market view is only relevant from an organizational perspective and within a business domain, which is, however, not always useful in capturing the multiple domains in which a digital disruption can take root. Similarly, most of the discourse around digital innovations have focused on its affordance for value creation in contrast with its propensity for value destruction. In this sense, digital disruption can be seen as one manifestation of digital innovation that emphasizes the disruptive effects that it triggers.

\section{References}

[1] Ansari, S., R. Garud, and A. Kumaraswamy, "The Disruptor's Dilemma: Tivo and the US Television Ecosystem", Strategic Management Journal 37, 2016, pp. 1829-1853.

[2] Baiyere, A., "Disrupted Disruptions: Lessons from Potential Disruptive Innovations that barely disrupted", Proceedings of The International Society for Professional Innovation Management (ISPIM), (2014).

[2] Baiyere, A., and Salmela, H. "Wicked yet Empowering - When IT Innovations are also Disruptive Innovations." In: ICIS 2015 Proceedings. (2015).

[3] Baiyere, A., and H. Salmela, "Disruptive innovation \& information technology-charting a path. In . RMIT University", 24th Australasian Conference on Information Systems (ACIS), (2013), 1-11.

[4] Benkler, Y., The Wealth of Networks - How
Social Production Transforms Markets and Freedom, Yale University Press, New Haven and London, 2006.

[5] Bharadwaj, A., O.A. El Sawy, P.A. Pavlou, and N. Venkatraman, "Digital Business Strategy: Towards a Next Generation of Insights", MIS Quarterly 37(2), 2013, pp. 471-482.

[6] von Briel, F., P. Davidsson, and J. Recker, "Digital Technologies as External Enablers of New Venture Creation in the IT Hardware Sector", Entrepreneurship Theory and Practice, 2018, pp. 123.

[7] Bughin, J., and N. Van Zeebroeck, "The best response to digital disruption", MIT Sloan Management Review 58(4), 2017, pp. 80-86.

[8] Christensen, C., "Disruptive innovation is a strategy, not just the technology", Business Today, 2015, pp. 150-158.

[9] Christensen, C.M., The Innovator's Dilemma When New Technologies Cause Great Firms to Fail, Harvard Business School Press, 1997.

[10] Christensen, C.M., and M. Overdorf, "Meeting the Challenge of Disruptive Change", Harvard Business Review 78(1), 2000, pp. 67-76.

[11] Christensen, C.M., and M. Raynor, The innovator's solution: Creating and sustaining successful growth, Harvard Business Review Press., 2007.

[12] Daneels, E., "Dialogue on the effects of disruptive technology on firms and industries", Hournal of Product Innovation Management 23(1), 2006, pp. 2-4.

[13] Fichman, R.G., B.L. Dos Santos, and Z. Zheng, "Digital Innovation as a Fundamental and Powerful Concept in the Information Systems Curriculum", MIS Quarterly 38(2), 2014, pp. 329-353.

[14] Gilbert, R.J., "E-books: A tale of digital disruption", of Economic Perspectives 29(3), 2015, pp. 165-184.

[15] Gladwell, M., "Annals of Innovation: How David Beats Goliath", The New Yorker, 2009. [16] Govindarajan, V., and P.K. Kopalle, "The usefulness of measuring disruptiveness of innovations ex-post in making ex-ante predictions."”, Journal of Product Innovation Management 23(1), 2013.

[17] Henfridsson, O., and B. Bygstad, "The Generative Mechanisms of Digital Infrastructure Evolution”, MIS Quarterly 37(3), 2013, pp. 907-931. [18] Henfridsson, O., J. Nandhakumar, H. Scarbrough, and N. Panourgias, "Recombination in the open-ended value landscape of digital innovation", Information and Organization 28(2), 2018, pp. 89-100.

[19] Hukal, P., and O. Henfridsson, "Digital 
Innovation - A Definition and Integrated Perspective", In R.D. Galliers and M.-K. Stein, eds., The Routledge Companion to Management Information Systems. Routledge, 2017, 360-369. [20] Kallinikos, J., A. Aaltonen, and A. Marton, "The Ambivalent Ontology of Digital Artifacts", MIS Quarterly 37(2), 2013, pp. 357-370.

[21] Karimi, J., and Z. Walter, "The role of dynamic capabilities in responding to digital disruption: A factor-based study of the newspaper industry", Journal of Management Information Systems 32(1), 2015, pp. 39-81.

[22] Keller, A., and S. Hüsig, "Ex ante identification of disruptive innovations in the software industry applied to web applications: The case of Microsoft's vs. Google's office applications.”, Technological Forecasting and Social Change 76(8), 2009, pp. 1044-1054.

[23] King, A.A., and B. Baatartogtokh, "How useful is the theory of disruptive innovation?.", MIT Sloan Management Review 57(1), 2015, pp. 77-81.

[24] Lee, J., and N. Berente, "Digital Innovation and the Division of Innovative Labor: Digital Controls in the Automotive Industry", Organization Science 23(5), 2012, pp. 1428-1447.

[25] Lusch, R.F., and S. Nambisan, "Service

Innovation: A Service-Dominant Logic Perspective", MIS Quarterly 39(1), 2015, pp. 155-176.

[26] Lyytinen, K., and G.M. Rose, "The Disruptive Nature of Information Technology Innovations: The Case of Internet Computing in System Development Organizations", MIS Quarterly 27(4), 2003, pp. 557596.

[27] Lyytinen, K., C. Sørensen, and D. Tilson, "Generativity in Digital Infrastructures: A Research Note”, In R.D. Galliers and M.-K. Stein, eds., The Routledge Companion to Management Information Systems. 2018.

[28] Lyytinen, K., Y. Yoo, and R.J. Boland, "Digital product innovation within four classes of innovation networks", Information Systems Journal, 2016, pp. 47-75.

[29] Maranville, S., "Entrepreneurship in the business curriculum", Journal of Education for Business 68(1), 1992, pp. 27-31.

[30] Markides, C., "Disruptive innovation: In need of better theory", Journal of Product Innovation

Management 23(1), 2006, pp. 19-25.

[31] Mohr, S., and O. Khan, "3D printing and its disruptive impacts on supply chains of the future.", Technology Innovation Management Review 5(11), 2015.

[32] Nambisan, S., "Information Technology and Product / Service Innovation: A Brief Assessment and Some Suggestions for Future Research", Journal of the Association for Information Systems 14(Special Issue), 2013, pp. 215-226.

[33] Nambisan, S., K. Lyytinen, A. Majchrzak, and M. Song, "Digital Innovation Management:

Reinventing Innovation Management Research in a Digital World", MIS Quarterly 41(1), 2017, pp. 223238.

[34] Riemer, K., and R.B. Johnston, "Disruption as worldview change: A Kuhnian analysis of the digital music revolution", Journal of Information Technology, 2019.

[35] Schmidt, E., and J. Cohen, "The Digital Disruption-Connectivity and the Diffusion of Power", Foreign Affairs 89(75), 2005.

[36] Skog, D.A., H. Wimelius, and J. Sandberg, "Digital Disruption", Business \& Information Systems Engineering 60(5), 2018, pp. 431-437. [37] Tilson, D., K. Lyytinen, and C. Sørensen, "Research Commentary - Digital Infrastructures: The Missing IS Research Agenda", Information Systems Research 21(4), 2010, pp. 748-759.

[38] Utesheva, A., J.R. Simpson, and D. CecezKecmanovic, "Identity metamorphoses in digital disruption: a relational theory of identity", European Journal of Information Systems, 25(4), 2016, pp. 344-363.

[39] Yoo, Y., R.J. Boland, K. Lyytinen, and A. Majchrzak, "Organizing for Innovation in the Digitized World”, Organization Science 23(5), 2012, pp. 1398-1408.

[40] Yoo, Y., O. Henfridsson, and K. Lyytinen, "The New Organizing Logic of Digital Innovation: An Agenda for Information Systems Research", Information Systems Research 21(4), 2010, pp. 724735.

[41] Yu, D., and C.C. Hang, "A Reflective Review of Disruptive Innovation Theory", International Journal of Management Reviews 12(4), 2010, pp. 435-452. [42] Zittrain, J., "The Generative Internet", Harvard Business Review 119(7), 2006, pp. 1974-2040. 